\title{
Examining Preservice Teachers' Self-Reported Knowledge and Confidence to Communicate With Parents
}

\author{
Nancy Maynes, Tracey Curwen, and Glynn Sharpe \\ Nipissing University
}

\begin{abstract}
This paper reports on one aspect of a larger study to examine the relationship between preservice teachers' self-reports of their levels of knowledge and confidence concerning many key areas of professional knowledge and skills. Knowledge and confidence in working with parents were examined using information provided by current and recently graduated concurrent and consecutive bachelor of education students. Results indicate that although knowledge remains consistent over the course of concurrent education, confidence does increase between Year 1 and 3 , but then remains constant. Recent graduates do not feel overly knowledgeable or confident in their ability to communicate with parents. However, consecutive students reported significantly more knowledge and confidence compared to concurrent students. Because communicating with parents is a key expectation of professional teachers, this finding is important. The results of this research support the need for additional strategic instruction and practice to develop skills related to communicating with parents in teacher preparation programs.
\end{abstract}

Keywords: teacher education programs; parents; communication 


\section{Examining Preservice Teachers' Self-Reported Knowledge and Confidence to Communicate With Parents}

This paper reports on a study regarding whether or not preservice teachers feel confident in their communication with parents about their child's progress and the school curriculum; this study was part of a larger investigation of teachers' perceptions of their knowledge and skills in various teaching responsibilities. The focus of this study is teacher self-confidence regarding communicating with parents; self-confidence is defined as being "sure of oneself" (Agnes, 1997, p. 254). As such, we are investigating how sure teachers' are of their ability to communicate with parents.

A considerable amount of educational literature is devoted to highlighting the importance of a strong partnership between teachers and parents for the benefit of students (Hargreaves, 2000); however, little evidence is available regarding how teachers are to acquire the skill set required to build this partnership (Ravn, 2003). Programs have been developed to focus on preservice teachers' skills and efficacy in dealing with parents in low socio-economic situations (Hoover-Dempsey, Walker, Jones, \& Reed, 2002); however, there is no literature on the preservice teachers' perceptions of their readiness or confidence to assume this key requirement of their profession.

It is believed that a strong parent-teacher relationship and successful collaboration between the two (for the benefit of the child) depends on the teacher (Hargreaves, 2000). The classroom is the teacher's territory of influence. A teacher must initiate and sustain a positive teacher-parent partnership. However, some teachers find it difficult to relate professionally to adults; this reflects the nature of their professional training, which is almost exclusively focused on developing the skills required to relate to children (Ravn, 2003). It is believed that outstanding teachers communicate regularly with students' parents and that understanding the child's family is essential when working effectively with the child (Hiatt-Michael, 2001; Epstein, 2001). The ability to measure the confidence and knowledge that preservice teachers report about their own abilities in relation to communication with parents is a first step towards assessing program offerings and towards helping to determine whether this area of knowledge is adequately addressed in their teacher preparation courses.

\section{Literature Review}

Many promising methods of creating and sustaining coordinated teacher-parent partnerships have been identified for use in teacher preparation programs (Hiatt-Michael, 2001). These methods include acquiring skills for positive home-school communication, giving teacher candidates opportunities to observe and critique parent-teacher conferences, applicable case studies, home visits, home/school literacy programs, newsletters, participating in school advisory councils, gathering important information from parents, exploring strategies for dealing with difficult situations (role playing), and strategies for connecting with the parent either in person or by telephone. It may be possible to pursue these strategies in teacher preparation programs, but opportunities to acquire this type of training in the profession are very limited (Ravn, 2003); therefore, specific program design parameters may be required to ensure that every preservice teacher has an opportunity to acquire this knowledge and be confident when implementing such measures. Additionally, preparation courses may not provide clarity and training to help new teachers understand the possibilities for different levels of parent engagement in schools 
(Epstein, 2001). As well, many researchers have identified the failure of teacher education programs to address family involvement in schooling (Allexsaht-Snider \& Schwartz, 2001; Chavkin \& Williams, 1988; Foster \& Loven, 1992; Shartrand, Kreider, \& Erickson-Warfield, 1994; Williams, 1992; Williams \& Chavkin, 1984).

While some programs exist that do address teachers' preparation to work collaboratively with parents and families (Allexsaht-Snider, Martinez, \& Phitiaka 1996; Corrigan, 1996; Shartrand, Weiss, Kreider \& Lopez, 1997) little research has been conducted on the theoretical and conceptual foundations of these programs (Hiatt-Michael, 2001). Hiatt-Michael (2001) also notes that few reports of studies analyzing teachers' and teacher education candidates' efforts to make sense of their learning about family involvement in schooling (and to apply this understanding to their work in schools) are available. Many key theoretical frameworks could help course instructors plan preservice learning in this area. These include the following:

- Bronfenbrenner (1979) - ecological theory;

- Epstein (1990) - overlapping spheres of influences and the typology of parental involvement;

- Chavkin \& Williams (1993) - four-part framework for ways to work with parents, including personal, conceptual, practical, and contextual levels;

- Bronfenbrenner (1979) - ecological theory;

- Mall, Amanti, Neff \& Gonzalez (1992) - family funds of knowledge;

- Allexsaht-Snider (1995) - socially constructed knowledge from interactions; and

- Edwards, Pleasants, \& Franklin (1999) - parents' construction of cultural knowledge about family-school relationship.

However, in the context being studied, it is exclusively the decision of individual course instructors if they plan to address specific theories or strategies related to parental communication in their respective courses. A study to identify the status of preservice teachers' knowledge and confidence in communicating with parents would provide important information regarding whether or not current programs and courses should be altered or further developed to aid preservice teachers with this vital means of communication.

\section{Background/Context for the Study}

Theories may provide the knowledge that teacher candidates require to work effectively with parents and families to support a child's education. However, without opportunities to apply these theories to practice during teacher preparation, candidates may lack the necessary confidence to address new contexts with equal effectiveness. In addition, without research to support the use of any or all of these theories, the efficacy and utility of each remains unknown.

In some existing courses, teacher candidates learn to understand the complexities of family life, understand themselves as members of a community, and recognize ways that other community members influence the lives of families and the children in them (Bucci \& Reitzammer, 1992; Flanigan, 2007; Hoover-Dempsey, et al., 2002). Additionally, some courses may provide guidance about how the community can support teachers and families (Morris, 
Taylor, \& Knight, 1998) and provide practical strategies for working with parents and communities (McCaleb, 1994; Moll, Amanti, Neff, \& Gonzalez, 1992, Orman, 1993; Valentine, 1984; Vopat, 1994).

Courses addressing partnerships with parents should support the new teacher's emerging understanding of the increasingly multicultural nature of the communities in which they serve. Course discussions about parental involvement in schools should examine traditional assumptions about this relationship (Curran, 1989), investigate barriers and supports to encourage family involvement in schools (Moles, 1993), and consider models for engaging families in the school in active ways (Epstein, 1990; Swap, 1993). Courses that include realistic opportunities to interact with families in diverse circumstances and reflect on those interactions may provide a basis for developing a positive view of family involvement. These opportunities should assist to balance the tendency of new teachers and teacher candidates to see their communication efforts from a deficit perspective; that is, without professional instruction, new teachers may inaccurately see one of their roles being the need to provide ways to address family dynamics (Hiatt-Michael, 2001). Preservice teachers can and do change their attitudes and beliefs about families by working directly with issues related to families (Bucci \& Reitzammer, 1992; Morris et al., 1998). With the potential to create attitudinal changes, teacher preparation programs with the most dynamic strategies have the ability to influence positively partnerships with parents and families. When addressing this important professional responsibility, developing preservice teachers' knowledge and confidence in a proactive manner is of the utmost importance.

Additionally, a rich theoretical background about parents' perspectives on their roles in their children's schooling has evolved and can provide structure for preservice programs (Boutte, 1992; Chavkin \& Williams, 1993; Cook \& Fine, 1995; Delgado Gaitan, 1992; Finders \& Lewis, 1994, Yao, 1993). With a background in family dynamics and parental involvement efforts in schooling, teacher candidates and new teachers could develop a school culture based upon twoway communications with families, where they both teach and learn from families (AllexsahtSnider \& Schwartz, 2001). The evidence shows that cooperation between parents and schools supports teachers' task performance in their teaching roles (Netherlands study, 2001). This is a powerful incentive to ensure that new teachers have both the knowledge and confidence to work effectively with parents and families.

Katz and Bauch (1999) found that courses addressing parent involvement issues affect classroom practice; however, it is unknown how well preparation programs that address forms of home-school partnerships are preparing new teachers to communicate with parents effectively. Some programs to support preservice teachers are offered in faculties of education but are based on studies from a specific type of parental group and this may limit broad applicability (Flanigan, 2007; Hoover-Dempsey et al., 2002). Practical involvement for parents in partnerships may include interactive homework, parent workshops, and newsletter development. However, planning and sustaining coordinated year-long partnerships may create time challenges for working parents and communication challenges for immigrant parents, as well as additional demands on the classroom teacher.

A number of researchers, including Bennett and Carre (1993), have highlighted the dearth of empirical investigation into the content and impact of teacher education courses. Given that the goals of Faculties of Education include instilling confidence in teacher candidates, it is 
surprising that very little empirical research has been conducted to determine whether this objective has been achieved. Research into preservice teacher confidence has primarily focused on teaching specific courses such as science math (Brady \& Bowd, 2005; Li \& Kulm, 2008; Swetman, Munday, \& Windham, 1993; Tekkaya, Cakiroglu, \& Ozkan, 2004), and music (Ebbeck, Yim, \& Lee, 2008). Results of these studies indicate that even with limited knowledge, preservice teachers report feeling confident in their abilities ( $\mathrm{Li} \& \mathrm{Kulm}, 2008$ ). Others have found that in-service teachers were significantly more confident $(M=32.6)^{1}$ than the preservice teachers $(M=29)$ in their confidence to teach music (Ebbeck, et al., 2008). Of note, Ebbeck et al. (2008) assessed confidence using 10 music questions resulting in a total score that ranged between 10 (not at all confident) to 50 (very confident) and the mean confidence scores of 29 and 33 indicates that neither group was, on average, overly confident.

Interestingly, therefore, previous research suggests that having knowledge is not a requirement for feeling confident about teaching subject matter and feeling confident is not a reflection of having a good knowledge base (Brady \& Bowd, 2005; Ebbeck, et al., 2008; Li \& Kulm, 2008; Swetman et al., 1993; Tekkaya et al., 2004). However, it is important to note that the research discussed was a cross-sectional study and it may be that over time, confidence, as well as knowledge change.

It is clearly important that to study confidence in preservice teachers a measure of knowledge must also be incorporated since one of these aspects of teaching is not necessarily indicative of the other. Therefore, we asked preservice teachers to respond to several items about their perceptions of both their knowledge and their confidence in relation to many requirements of a teacher's role, including their confidence and knowledge to communicate effectively with parents.

Little empirical research has been conducted to investigate the general confidence of preservice teachers, with most of the evidence to date reflecting confidence in specific subject areas. While research about efficacy is related, efficacy is an indicator of skill, rather than selfperceived knowledge and confidence. Since efficacy, knowledge, and confidence are distinctly different, it was decided that we would focus on connections between knowledge acquisition and growth in confidence, since these measures can be indicated through self-assessment while efficacy or skill level might be better measured using an external evaluator's opinion.

Research has demonstrated that preservice teachers' confidence and knowledge in a subject area are not interchangeable; knowledge and confidence may conflict in other duties, such as working with parents. To date, we know of no empirical investigation into preservice teachers' knowledge and confidence to interact with parents, although other studies examine existing programs to support preservice curriculum to address this area of professional growth (Flanigan, 2007; Hoover-Dempsey et al., 2002).

In Ontario, teacher education is organizing into two streams: consecutive and concurrent, with an Orientation to Teaching (OTT) entry path to the consecutive stream being an option in some institutions as well. The consecutive model requires prospective teachers to complete a Faculty of Education program only after completing an undergraduate degree. On the other hand, in the concurrent model, prospective teachers complete courses towards an undergraduate degree while also taking education specific courses. Regardless of the teaching stream, the goal of teacher education is to provide prospective teachers with the knowledge and confidence 
necessary to be effective teachers, including their ability to communicate effectively with parents.

An investigation into the trajectories for confidence levels of concurrent education students during the course of their 5 years in the program will be beneficial; having this knowledge will allow program developers to identify areas in which preservice teachers feel more or less confident, identify when confidence levels change and whether this is tied to the number of years in the program, and allow those with program design responsibilities to adapt and improve the program to ensure the fidelity of these aspects of the program. Comparing the knowledge and confidence of students completing these distinctly different accreditation routes will be useful for making program design decisions.

The study was designed to contribute information to address the dearth of empirical investigation into the content and impact of teacher education courses. Our focus was to determine whether recently graduated teacher candidates feel confident and knowledgeable in interacting with parents, whether and how confidence and knowledge change over the course of teacher preparation, and to compare confidence and knowledge between concurrent and consecutive preservice and in-service teachers.

\section{Method}

\section{Participants}

Participants were from both the consecutive and the concurrent programs at three campuses from one Northern Ontario university. A total of 212 respondents (25 males, 186 females, 1 gender not reported) completed the survey and were include in the study. Respondents ranged in age between 18 and 58 years old $(M=23.18, S D=4.91)$. Respondents were completing or had completed a consecutive teacher preparation program $(n=81)$ or were completing or had completed the concurrent program $(n=131)$.

Demographic data was collected to identify the details of each respondent's program route and the stage of completion of their teacher preparation. Of the 131 concurrent education respondents, 2 were in the 1st year of their program, 23 in the 2 nd year, 26 in the 3 rd year, 28 in the 4th year, and 31 were in the final year or recently graduated from their teacher education program. Twenty-one respondents had previously graduated.

\section{Measures}

Demographics. Data about age, gender $(0=$ male, $1=$ female $)$, current status in the education program (i.e., year of concurrent program, graduated from consecutive or concurrent), were collected for descriptive information and to investigate relationships between demographics and dependant variables.

Knowledge. A total of five questions developed by the researchers were used to assess knowledge regarding communication with parents. The following question was included: Do you have enough knowledge regarding: (a) communication with parents, (b) methods of communication, (c) completion of progress reports, (d) completion of report cards, and (e) methods of communication. Questions were responded to on a 5-point scale from 0 (definitely not) to 4 (definitely). Total scores could range between 0 and 20; higher scores indicated more knowledge. Internal consistency was very good $(\alpha=.87)$. 
Confidence. A total of seven questions developed by the researchers were used to assess confidence in communicating with parents. Questions were responded to on a 5-point scale with 0 (definitely not) to 4(definitely); total scores could range between 0 to 28 with higher scores indicating more confidence. Questions assessing confidence included the following: Are you confident in your ability to: (a) explain your classroom program to parents/ guardians?,(b) address concerns about a student's progress during a one-on-one meeting with a parent/guardian?, (c) address concerns about a student's behaviour with a parent/guardian?, (d) explain a student's progress effectively on progress reports?, (e) address concerns about a student's progress during a one-on-one meeting with a parent/guardian?, (f) use electronic newsletters to communicate with parents/guardians?, and (g) use classroom newsletters to communicate with parents/guardians? Internal consistency was very good $(\alpha=.92)$.

\section{Procedure}

An invitation to participate in the study was posted on an existing Facebook group page designed to give professional support among teacher candidates. A brief description of the purpose of the study and a link to the information letter was provided. Those who were interested followed the link to the information sheet, which provided all the information necessary for informed consent.

Upon completion of reading the introductory letter, potential participants could agree to continue or could exit the program. Completion of the questionnaire indicated each respondent's agreement to participate in the study. One reminder of the opportunity to participate in the survey research was posted on the Facebook site 1 month after it was first advertised. Data collection was started in April 2011 and was completed by mid-June 2011. Completion of the entire questionnaire required approximately 15 minutes.

\section{Results}

Gender and age of respondents were assessed to determine whether differences existed and would need to be accounted for in further analyses. Males and females from all years were compared ( $n=21$ males; $n=167$ females). Similar confidence scores were reported by males $(M$ $=16.28, \mathrm{SD}=4.23)$ and females $(M=17.26, S D=5.94)(t(186)=-0.74, \mathrm{p}>.05)$. Males $(M=$ 9.25, $S D=4.32)$ and females $(M=10.05, S D=4.18)$ also reported similar knowledge scores $(\underline{t}(205)=-0.88, p<.05)$. Since no gender differences were found, male and female respondents were combined for further analysis. Age was not correlated with total knowledge $(r=-.018, p>$ $.05)$ and weakly correlated with confidence $(r=0.26, p<.05)$. That is, those preservice teachers who were older reported slightly more confidence to communicate with parents. 
We next investigated whether knowledge and confidence increase over the course of a 5year concurrent education program. Figure 1 shows that knowledge about how to deal with parents seems to stay similar over time, but confidence in one's ability to communicate with parents increases between Years 1 and 3 and remains stable between Years 3 and 5.

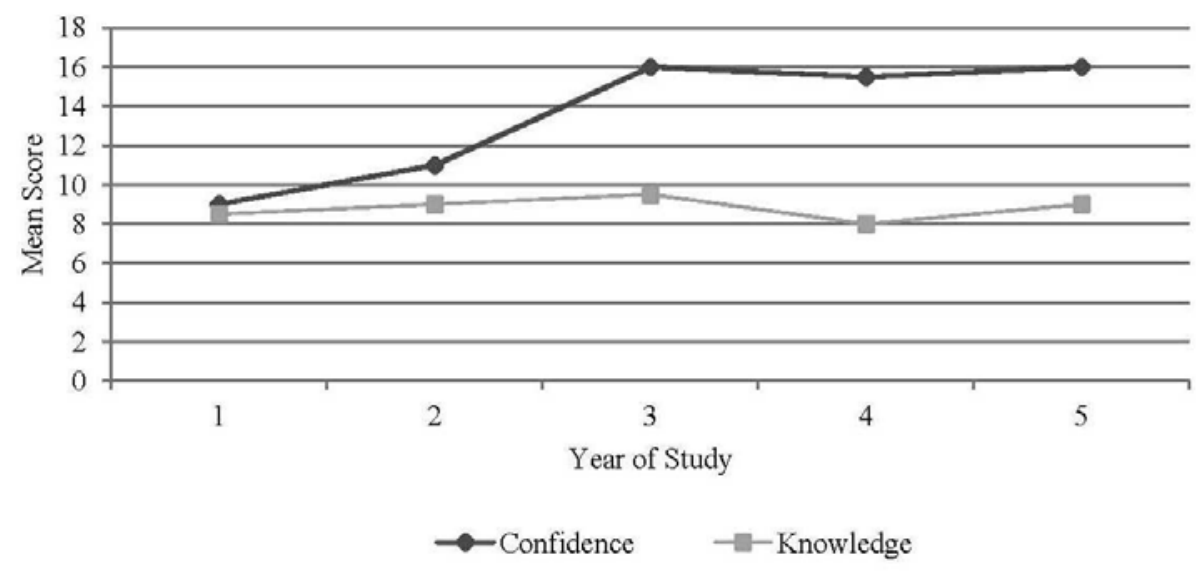

Figure 1. Knowledge and Confidence Over Time in Concurrent PreService Teachers' SelfReported Knowledge and Confidence to Communicate with Parents

To understand further whether preservice teachers feel confident and knowledgeable regarding interactions with parents, we investigated only those in their $5^{\text {th }}$ year of their teacher preparation program to determine whether all current graduates feel prepared to interact with parents and then determine whether differences exist between graduates from concurrent and consecutive programs. All respondents who graduated in 2011 were included in further analyses. This sample included 24 consecutive respondents and 42 concurrent program respondents, 6 males and 60 females; responses were combined since previous analysis had shown no difference across gender. This group ranged in age from 23 to $53(M=23.19, S D=3.92)$.

We first investigated overall confidence and knowledge scores for recent graduates. Overall knowledge scores indicate moderate knowledge; the total score (all combined knowledge questions) could range from 0 to 20; the total confidence score also indicated moderate confidence as scores could range from 0 to 28 . These scores indicate that the graduating teachers, at the end of their education programs, do not feel overly knowledgeable or confident in their ability to communicate with parents.

The final main issue to investigate was to compare concurrent and consecutive graduates to determine whether program may affect knowledge and confidence. Age was compared between the concurrent and consecutive respondents as age was related to confidence in the full sample. There was a significant age difference between consecutive $(M=24.88, S D=6.10)$ and concurrent $(M=22.24, S D=1.04)$ program graduates $(t(70)=2.89, p<.01)$; therefore, age was covaried in comparisons between graduates. The relationship between concurrent graduates' knowledge and confidence was not significant $(r=.24, p>.05)$; however, it is likely that with a larger sample the results would demonstrate a significant but weak relationship. 
On the other hand, a strong relationship between knowledge and confidence was found for the consecutive students $(r=.67, p<.001)$. Based on these results, it can be concluded that having knowledge does not suggest feelings of confidence for concurrent students, but those consecutive graduates who feel they have knowledge of communicating with parents also report feeling confident in communicating with parents.

To compare knowledge and confidence between concurrent and consecutive graduates, a MANOVA with age covaried was conducted; the results indicate differences in knowledge $(F(1$, $65)=5.63, p<.05)$ and confidence $(F(1,65)=5.01, p<.05)$. Mean scores are provided in Figure 2; consecutive graduates reported higher knowledge and confidence than their concurrent counterparts. Of note, both groups were in the moderate range for knowledge and confidence. These results indicate that concurrent and consecutive graduates report not feeling overly

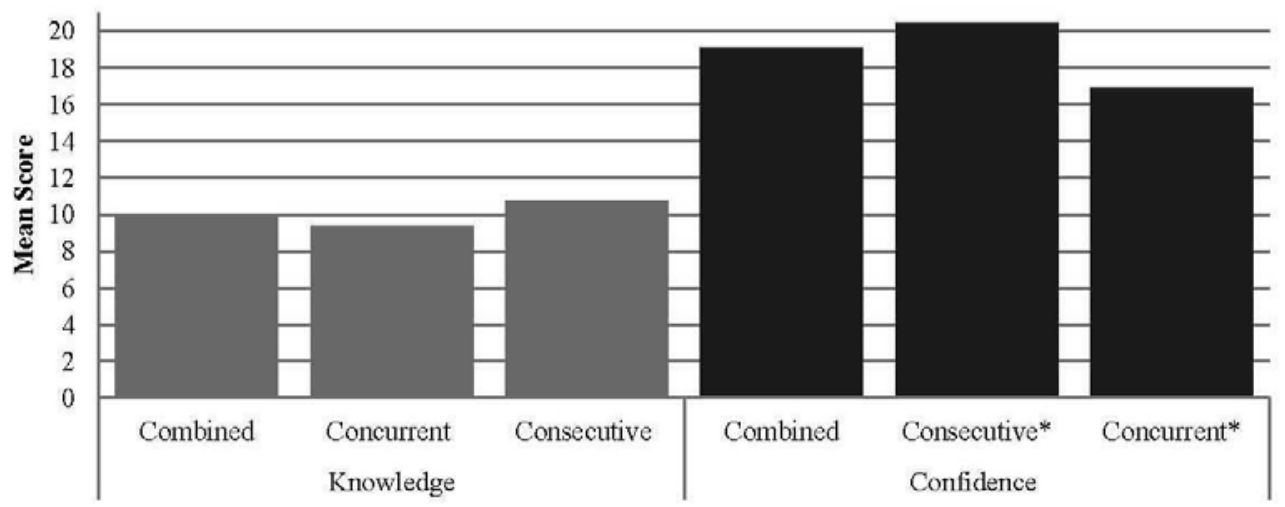

knowledgeable or confidant regarding communicating with parents.

$* p<.05$ Knowledge range 0-20; Confidence range 0-28

Figure 2. Knowledge and confidence for all graduates and concurrent and consecutive graduates 
To understand whether specific aspects of confidence differed between concurrent and consecutive students, each of the questions used to assess confidence was compared between the

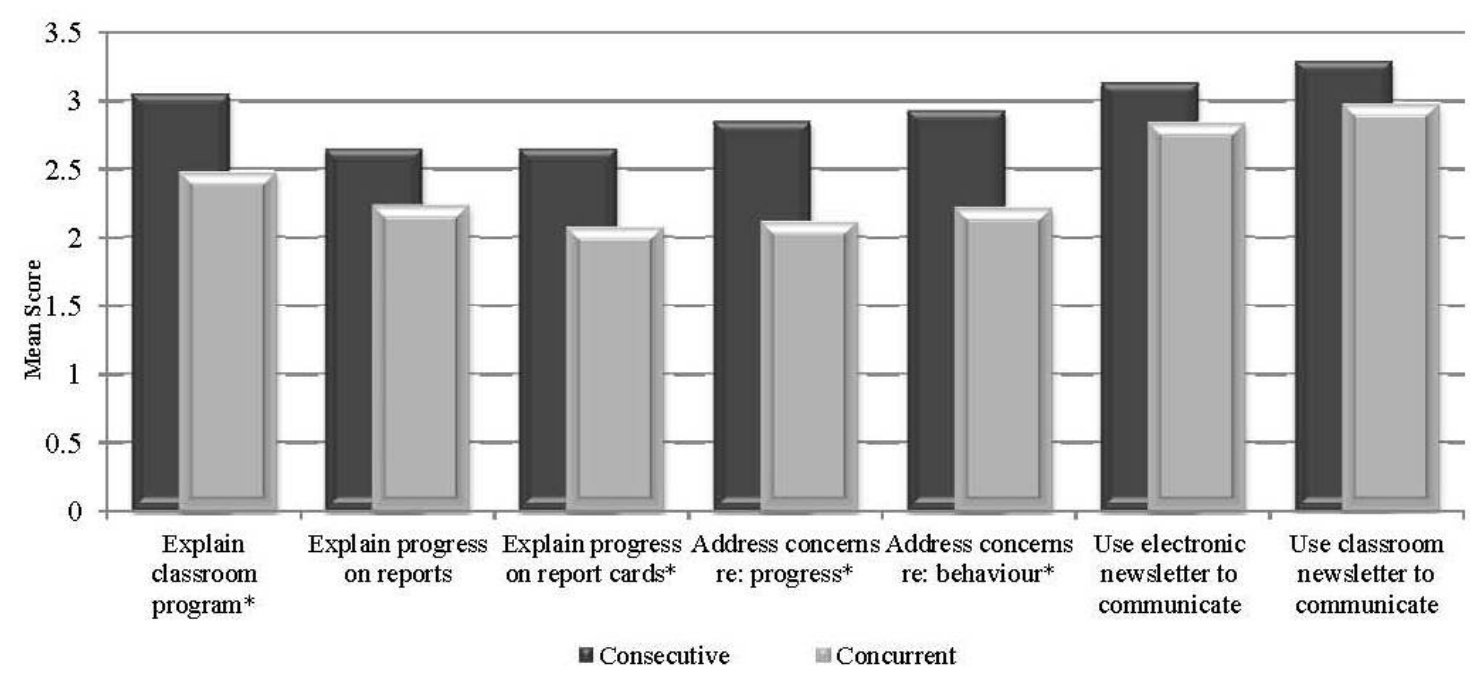

groups. The results are presented in Figure 3.

Figure 3. Questions Assessing Confidence to Communicate with Parents.

${ }^{*} p<.05$ Knowledge range 0-20; Confidence range 0-28

As can be seen in Figure 3, consecutive students reported higher scores on their confidence to explain their classroom to parents, to explain a student's progress on progress reports and report cards, to address concerns with parents regarding the student's progress and behavior, and to use either newsletters or electronic newsletters to communicate with parents.

\section{Discussion}

This cross-sectional study was an attempt to understand the knowledge and confidence of current and recently graduated education students regarding their knowledge and confidence when communicating with parents. Results indicate that knowledge remains consistent and moderate throughout concurrent education; however, between the $1^{\text {st }}$ and $3^{\text {rd }}$ year of concurrent education, confidence to communicate with parents increases and then remains stable until program completion. We were surprised to find that that there is relatively little change in participants' knowledge and confidence to communicate with parents between Years 3 and 5 of their 5-year concurrent education program. Confidence over these years remained relatively consistent despite the accumulation of practice teaching time in schools. This result brings into question the opportunities for exposure to working with parents at any stage of the program.

When comparing graduating teachers from consecutive or concurrent programs, results indicate that both do not feel overly knowledgeable or confident in their ability to communicate with parents. However, consecutive students do report more confidence than concurrent students. Communicating with parents is a key expectation of teachers. Our findings indicate the need for additional instruction and practice to develop the required knowledge and confidence related to communicating with parents in teacher preparation programs. Programs developed at other 
teacher education institutions may be beneficial resources for programs where preservice teachers seem to lack knowledge or confidence to address parents (Flanigan, 2007; HooverDempsey et al., 2002).

While preservice teachers may have an opportunity to participate in interactions with parents in many practice teaching contexts during the program, the opportunity for interaction with parents, and therefore practice to ensure efficacy, is by no means guaranteed. The context of the teaching practica varies greatly for every teacher candidate and some may lack important opportunities for such interaction. While common sense would suggest that with more practicum placement time there would be more opportunities for parent-teacher communication and, in turn, more time to develop knowledge and confidence with communicating with parents, our results do not support this assumption. Those preservice teachers with the greater amount of practicum time were the concurrent students ( 23 weeks over 5 years); consecutive preservice teachers, by contrast, typically experienced 12 weeks of practicum over 8 months. As concurrent students experience more classroom time and likely more communication with parents compared to consecutive students, we were surprised to find that consecutive students claimed more knowledge and confidence in communicating with parents.

While we cannot, from this study, say conclusively what has caused the differences in the confidence reported by the two graduating teacher groups in relation to communicating with parents, several key issues have been considered. It may be that, overall, the practicum experience in either program may not be either extensive enough and/or not focused enough on key learning experiences to provide the needed exposure to communicating with parents. In addition, we wonder if more practicum experience may increase the potential for younger preservice teachers to have more negative experiences with parents over the course of their 5year program. It seems intuitive that the nature of the communication with parents during practica will have a substantial impact on confidence in dealing with parents. It may also be possible that the diffused focus of practicum experiences spread over 5 years in a concurrent education program may not allow the interaction that would support strong positive communication with parents. Finally, consecutive students' brief exposure to parents during practicum weeks may leave them unaware of the reality of various issues when communicating with parents regarding both negative and positive situations.

We also found a strong relationship between knowledge and confidence for the consecutive but not the concurrent students. As concurrent education students have almost twice as much exposure to classrooms, and therefore more opportunities to interact with parents during practicum placements, it is possible that concurrent preservice teachers rely on their experiences to evaluate their competence to communicate with parents. On the other hand, consecutive students, with about 12 weeks of possible interaction with parents, may rely more on what they have learned in their academic program (i.e., knowledge regarding communicating with parents) to report their own feelings of confidence.

As both concurrent and consecutive graduating students reported only moderate knowledge and confidence in communicating with parents, it seems B.Ed. students (5th year) may need added instruction or assistance to improve knowledge and confidence related to these important teacher responsibilities. It would also be useful for future program decisions if we were to reassess these respondents after their first year of teaching. This would allow us to determine if there is any increase in teachers' knowledge and/or confidence with professional on- 
the-job exposure to related tasks and to see if differences in knowledge and confidence measures persist after the first year of practice. Hargreaves (2000) identified both positive and negative outcomes of parent interactions on teachers. On the positive side, parents could express gratitude, appreciation, agreement, and support for the teacher's actions. On the negative side, the teacher's academic purposes and expertise could be challenged, teachers could lack active parental support related to behavioural issues, and the professional and physical differences in the working realities of parents and teachers could cause a social-cultural distance. Negative experiences with parental contacts may make some teachers reluctant to continue to make these contact efforts. Knowing how preservice teachers feel about their readiness to address their professional communications with parents allowed us to examine how this population feels about their knowledge and confidence before they enter the profession and interact in either positive or negative contexts with parents. We examined measures of knowledge and confidence as indicators of preparation to engage and interact with parents.

Both Hiatt-Michael (2001) and Epstein (2001) elaborate on their research data that shows the benefits of working closely with families as partners in a child's education. The benefits they have found include: better student attendance, higher graduation rates, fewer retentions, increased parent and student satisfaction with education, more accurate diagnosis of students for special services, a reduction in negative behaviour reports for students, and higher achievement scores in reading and math. It would seem that such positive outcomes of partnerships with parents would direct our attention to ensuring that new teachers develop the knowledge and confidence that are necessary to form these partnerships. But, opportunities to work collaboratively with parents are influenced by many realities including finding an appropriate meeting time, finding space for a meeting, and the possibility of incompatible priorities between teachers and parents. Teachers may be further hampered in building the skills necessary to partner with parents because of the way their preparation time and professional development time is used. If time is focused on developing expertise through subject related courses, then preparation related to their professional affective development may be less than adequate (Ravn, 2003). However, given the benefits of communication, it is worthwhile to address obstacles to teachers' knowledge and confidence when initiating and sustaining contact with parents.

While a detailed discussion of programs to increase preservice teachers' knowledge of strategies to communicate with parents effectively is outside of the scope of this paper, readers are directed to the references provided earlier in the introductory sections of this summary to examine related studies and promising strategies. 


\section{References}

Agnes, M. (1997). Webster's new world pocket dictionary (3rd ed.). New York, NY: Simon \& Schuster, Inc.

Allexsaht-Snider, M. (1995). Teachers' perspectives on their work with families in a bilingual community. Research in Childhood Education, 9, 85-96.

Allexsaht-Snider, M., \& Schwartz, S. (2001). Family, school, and community interactions in teacher education and professional development: Integrating theoretical and conceptual frameworks. In F. Smith, K. Van de Wolf, \& P. Sleegers (Eds.), A bridge to the future: Collaboration between parents, schools, and communities (pp. 217-223). Nijmegan, The Netherlands: Institute for Applied Sciences.

Allexsaht-Snider, M., Martinez, R., Phtiaka, H. (1996, November). International perspectives: Preparing teachers for partnership. Paper presented at the Education is Partnership Conference, Copenhagen, Denmark.

Bennett, N., \& Carre, C. (1993). Learning to teach. London: Routledge.

Boutte, G. S. (1992). Frustrations of an African-American parent: A personal and professional account. Phi Delta Kappan, 73, 786-788.

Brady, P., \& Bowd, A. (2005). Mathematics anxiety, prior experience and confidence to teach mathematics among pre-service education students. Teachers and Teaching: Theory and Practice, 11(1), 37-46.

Bronfenbrenner, U. (1979). The ecology of human development: Experiments by nature and design. Cambridge, MA: Harvard University Press.

Bucci, J. A., \& Reitzmammer, A. F. (1992). Collaboration with health and social service professionals: Preparing teachers for new roles. Journal of Teacher Education, 43(4), 290 295.

Chavkin, N. F., \& Williams, D. L. (1988). Critical issues in teacher training for parent involvement. Educational Horizons, 66, 87-89.

Chavkin, N. F., \& Williams, D. L. (1993). Minority parents and the elementary school: Attitudes and practices. In N. F. Chavkin (Ed.), Families and schools in a pluralistic society (pp. 7383). New York: State University of New York Press.

Cook, D. A., \& Fine, M. (1995). 'Motherwit': Childrearing lessons from African-American mothers of low income. In B. B. Swadener \& S. Lubeck (Eds.), Children and families 'at promise': Deconstructing the discourse of risk (pp. 118-142). New York: State University of New York Press.

Corrigan, D., (1996). Teacher education and interprofessional collaboration: Creation of familycentered, community-based integrated service systems. In L. Kaplan \& R. A. Edelfelt (Eds.), Teachers for the new millennium: Aligning teacher development, national goals, and high standards for all students (pp. 142-177). Thousand Oaks, CA: Corwin Press. 
Curran, D. (1989). Reexamining traditional assumptions. In Working with parents (pp.17-31). Circle, Pines, MN: American Guidance Service.

Delgado Gaitan, C. (1992). School matters in the Mexican-American home. American Educational Research Journal, 29(3), 495-513.

Ebbeck, M., Yim, H. Y. B., \& Lee, L. W. M (2008). Music in early childhood education: Teachers' levels of confidence and happiness. Australian Journal of Music Education, 2, 2230.

Edwards, P. A., Pleasants, H. M., \& Franklin, S. H. (1999). A path to follow: Learning to listen to parents. Portsmouth, NH: Heinemann.

Epstein, J. L. (1990). School and family connections: Theory, research, and implications for integrating sociologies of education and family. In D. Unger \& M. Sussman (Eds.), Families in community settings: Interdisciplinary perspectives (pp. 99-126). New York: Haworth Press.

Epstein, J. (2001). Preparing educators and improving schools. Colorado: Westview Press.

Finders, M., \& Lewis, C. (1994). Why some parents don't come to school. Educational Leadership, 51, 50-54.

Flanigan, C. B. (2007). Preparing preservice teachers to partner with parents and communities: An analysis of college of education faculty focus groups. School Community Journal, 17(2), 89-109.

Foster, J. E., \& Loven, R. G. (1992). The need and directions for parent involvement in the 90's: Undergraduate perspectives and expectations. Action in Teacher Education, 14(3), 13-18.

Hargreaves, A. (2000). Professionals and parents: Personal adversaries or public allies? Prospects, 30 (2), 201-213.

Hiatt-Michael, D. B. (2001). Preparing teachers to work with parents. In F. Smit, K. van der Wolf, \& P. Sleegers (Eds.), A bridge to the future: Collaboration between parents, schools and communities (pp. 185-188), Nijmegen, Netherlands: Institute for Applied Social Sciences.

Hoover-Dempsey, K. V., Walker, J. M. T., Jones, K. P., \& Reed, R. P. (2002). Teachers involving parents (TIP): Results of an inservice teacher education program for enhancing parental involvement. Teaching and Teacher Education, 18, 843-867.

Li, Y., \& Kulm, G. (2008). Knowledge and confidence of pre-service mathematics teachers: the case of fraction division. Mathematics Education, 40, 833-843.

McCaleb, S. P. (1994). Co-authorship of books based on dialogs about education and life. In Building communities of learners: A collaboration among teachers, students, families, and community (pp. 97-137). New York: St. Martin's Press.

Moles, O. C. (1993). Collaboration between schools and disadvantaged parents: Obstacles and openings. In N. F. Chavkin (Ed.), Families and schools in a pluralistic society (pp. 21-49). New York: State University of New York Press. 
Moll, L. C., Amanti, C., Neff, D., \& Gonzales, N. (1992). Funds of knowledge for teaching: Using a qualitative approach to connect homes and classrooms. Theory Into Practice, 31(2), 132-141.

Morris, V. G., Taylor, S. I., \& Knight, J. (1998, April). Are beginning teachers prepared to involve families in education? Paper presented at the annual meeting of the American Educational Research Association, San Diego, CA.

Orman, S. A. (1993). Mathematics backpacks: Making the home school connection. Arithmetic Teacher, 40(6), 306-308.

Ravn, B. (2003). Cultural and political divergences in approaches to cooperation between home, school and local society in Europe. In S. Castelli, M. Mendel, \& B. Ravn (Eds.), School, family, and community partnerships in a world of difference and changes (pp. 9-18). Gdanski, Poland: Wydawnictwo Uniwersytetu Gdanskiego.

Shartrand, A., Kreider, H., \& Erickson-Warfield, M. E. (1994). Preparing teachers to involve parents: A national survey of teacher education programs. Cambridge, MA: Harvard Family Research Project.

Shartrand, A., Weiss, H., Kreider, H., \& Lopez, M. (1997). New skills for new schools: Preparing teachers in family involvement. MA: Harvard Graduate School of Education.

Swap, S. M. (1993). Developing home-school partnerships: From concepts to practice. New York, NY: Teachers College Press.

Swetman, B., Munday, R., \& Windham, R. (1993) Math anxious teachers: Breaking the cycle. College Student Journal, 22(4), 421-427.

Tekkaya, C., Cakiroglu, J., \& Ozkan, O. (2004). Turkish pre-service science teachers'understanding of science and their confidence in teaching it. Journal of Education for Teaching, 30(1), 57-66.

Valentine, T. (1984). Handbook: Resource packet for parent project. [Adapted from G. G. Darkenwald, \& T. Valentine, Parents learning to assist children in the elementary school: A workshop for parents.] Rutgers, NJ: The State University of New Jersey.

Vopat, J. (1994). A workshop approach to parent involvement. York, ME: Stenhouse.

Williams, D. (1992). Parental involvement teacher education: Challenges to teacher education. In L. Kaplan (Ed.), Education and the family (pp. 243-254). Boston, MA: Allyn \& Bacon.

Williams, D., \& Chavkin, N. (1984). Guidelines and strategies to train teachers for parent involvement (Report No. PS 014 868). Austin, TX: Southwest Educational Development Laboratory. (ERIC Document Reproduction Service No. ED 255- 289).

Yao, E. L. (1993). Strategies for working effectively with Asian immigrant parents. In N.F. Chavkin (Ed.), Families and schools in a pluralistic society (pp. 149-156). 


\section{Endnote}

${ }^{1}$ Notes regarding methods/results

\begin{tabular}{|l|}
\hline$M=$ mean score \\
\hline$S D=$ standard deviation of mean score \\
\hline$n=$ sample size \\
\hline$\alpha=$ Chronbach's alpha: measure of internal consistency of the items on a scale \\
\hline$t=t$-test, used to compare means between two groups; $t$ indicates whether or not there is a \\
significant difference between group means
\end{tabular}

